\title{
Breast-feeding in Europe - rationale and prevalence, challenges and possibilities for promotion
}

\author{
Agneta Yngve*, Elisabeth Kylberg and Michael Siöström \\ Unit for Preventive Nutrition, Department of Biosciences, Karolinska Institutet, SE-14157 Huddinge, Sweden
}

\begin{abstract}
The status reports and other information collected showed that interpretation of the data on breast-feeding prevalence and duration collected at national or regional level within European countries is difficult, since this information is not collected in every country or it is gathered under different criteria. However, there seem to be vast differences in prevalence of breast-fed children and breast-feeding duration between European countries and possibly within countries. There is a need to establish monitoring systems enabling comparability of data between countries. Assessing determinants for breast-feeding is required as well. There are a number of important consensus documents supporting breast-feeding action. These documents are related to either one or more of the following categories: health benefits of breastfeeding; recommendations regarding breast-feeding duration and exclusiveness; providing guidance on breast-feeding promotion. Current recommendation is exclusive breast-feeding for 6 months.
\end{abstract}

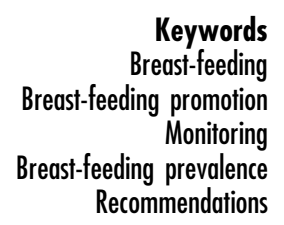

As background for the EURODIET recommendations to the European Union (EU) Commission, a rational for breast-feeding action in countries of the EU and the European Free Trade Association (EFTA) was produced, building on status reports and an overview of consensus documents and other relevant material. This paper summarises two EURODIET background papers ${ }^{1,2}$, and gives a brief overview of the results.

\section{Status reports regarding breast-feeding data}

The status reports and other information collected showed that interpretation of the data on breast-feeding prevalence and duration collected at national or regional level within European countries is difficult. This because:

- data are not collected in similar ways over Europe;

- data on exclusive breast-feeding are not collected;

- definitions are different regarding exclusiveness;

- reporting to World Health Organization (WHO) databases is not regular; and

- determinants of breast-feeding are seldom monitored.

Furthermore, some countries do not collect breastfeeding data on a regular basis. This leads to a confusing situation, where reported data are not comparable. It is therefore difficult at this stage to describe satisfactorily the breast-feeding situation in Europe. What can be said is that there seem to be vast differences in prevalence of breast-fed children and breast-feeding duration between
European countries and possibly within countries. Determinants need to be assessed as well.

It can be concluded that it is important to have a comparable system over Europe for monitoring of breastfeeding, including a suggested framework for assessing the most important determinants for breast-feeding. Ideally, it should be possible to use such a system at regional and local levels, for planning of promotional activities.

\section{Consensus documents and recommendations}

A number of consensus documents ${ }^{3-8}$ can be identified for the support of breast-feeding action. These relate to either one or more of the following categories:

- health benefits documents;

- recommendations regarding breast-feeding duration and exclusiveness; and

- providing guidance on breast-feeding promotion.

\section{The Innocenti Declaration ${ }^{3}$}

This document was the result of a joint WHO/United Nations Children's Fund (UNICEF) meeting in Florence, Italy in 1990. This is the most important and well-spread document in Europe so far. It includes all three categories of information, mostly focusing on recommendations and guidelines for promotion. The recommendation given is exclusive breast-feeding for 4 to 6 months. The document sets up a set of targets to be reached by the countries, 
mainly regarding structures for breast-feeding promotion, such as appointing a breast-feeding co-ordinator at national level, ensuring use of the 'Ten Steps to Successful Breastfeeding' in maternity care, take action for the International Code of Marketing of Breast Milk Substitutes and practise imaginative legislation protecting the breastfeeding rights of working women. The WHO European office is providing a follow-up on the country status of adhering to the Innocenti Declaration.

\section{WHO/UNICEF developments since Innocenti}

Early in 2000, a WHO/UNICEF expert panel expressed an informal consensus that the appropriate age for start of complementary feeding is about 6 months, rather than 4-6 months as in the Innocenti Declaration. At the same time, the WHO started up a systematic review regarding the optimal duration of exclusive breastfeeding. Based on this review, an expert consultation in late March 2001 endorsed the same optimal duration as the informal consensus, but used the term 'for six months' rather than 'about six months'. This was accepted as the official WHO recommendation and launched in early $2001^{4}$. The document includes a brief conclusion and recommendations for practice as well as for research.

\section{British Paediatric Association}

The document 'Is breastfeeding beneficial in the UK?' was published in $1994^{5}$. It gives a summary of the scientific background regarding breast-feeding and health benefits at the time. It does not include any recommendation, and there is no reference to breastfeeding promotion.

\section{American Dietetic Association (ADA)}

In the position statement 'Promotion of breast-feeding' from $1997^{6}$, the ADA declares 'Breastfeeding an infant for at least 6 months and preferably longer is not only optimal but should be the norm...' Further in the same document the same period appears as in the Innocenti Declaration: 4-6 months' exclusive breast-feeding. The document is clearly geared towards promotion and directed to all health professionals, but focusing on dietitians.

\footnotetext{
American Academy of Pediatricians (AAP)

This is probably the most comprehensive document ${ }^{7}$ that currently can be identified regarding breast-feeding issues. It contains a section on health benefits, a recommendation as well as a set of suggestions on the paediatrician's role in promoting, protecting and supporting breast-feeding. The recommended breast-feeding practice is exclusive for 6 months approximately and then partial up to 12 months at least.
}

\section{EURODIET}

The expert consultation for the European Commission regarding dietary guidelines and guidelines for a healthy lifestyle, which was finished and reported during $2000^{8}$, suggests a period of about 6 months' exclusive breastfeeding.

It can be concluded that the recommendation is currently exclusive breast-feeding for 6 months according to the most recent documents. This is an increase in duration compared with the Innocenti Declaration from 1990, which states 4-6 months' exclusive breast-feeding. It can also be concluded that there is currently no consensus document available that specifically relates to EU/EFTA countries regarding breast-feeding bealth benefits, recommendations and promotion of breastfeeding.

\section{Determinants for breast-feeding}

Determinants for breast-feeding ${ }^{2}$ can be categorised into the following areas.

- Demographic attributes - age, living area, size of family, marital status, education level, income and employment, etc.

- Psychosocial attributes - interpersonal and intrapersonal characteristics such as supportive social network, maternal health belief and confidence, self-efficacy, shyness, etc.

- Health care attributes and biomedical constraints health care routines, consistent advice, collaboration between health care and peer support groups, early discharge, prenatal classes, etc.

- Community attributes - local knowledge and action, breast-feeding in public accepted, workplace support, media advocacy, etc.

- Public policy - official recommendations, consensus statements, surveillance systems, maternity leave and benefits, marketing of breast-milk substitutes, training of health care staff, national plans of action to promote breast-feeding, etc.

It can be concluded that European-level support is needed to ensure the development of a manual for assessing a set of common determinants, for use at local as well as national level, aimed at designing targeted interventions to risk groups, as well as for design of national policy and support systems.

\section{Possibilities for promotion}

During the last decades, a number of countries have increased their breast-feeding rates substantially according to national data reported to the WHO Health For All Database $^{1,9}$. This can be seen to indicate that promotional efforts are well worthwhile and that improvements in 
breast-feeding rates can be made. The effectiveness of individual promotion measures needs to be further studied, in order to provide a set of promotional suggestions that can be used on local, national or international level. This work needs a thorough review of promotional efforts, which lists a set of success indicators and also a manual for design of future promotional programmes, including quality criteria for inclusion in systematic reviews.

It can be concluded that European-level support is needed to ensure that systematic reviews are performed regarding effectiveness of breast-feeding promotion programmes and that a manual for design of future bighquality promotional programmes is produced.

\section{References}

1 Yngve A, Sjöström M. Breastfeeding in countries of the
European Union and EFTA; current and proposed recommendations, rationale, prevalence, duration and trends. Public Health Nutr. 2001; 4(2B): 631-45.

2 Yngve A, Sjöström M. Breastfeeding determinants and a suggested framework for action in Europe. Public Health Nutr. 2001; 4(2B): 729-39.

3 WHO/UNICEF. The Innocenti Declaration on the Protection, Promotion and Support of Breastfeeding. Geneva: WHO/UNICEF, 1990.

4 http://whoint/nut/documents/optimal_duration_of_exc_bfeeding_eng.pdf. Accessed May 2001.

5 Statement of the Standing Committee on Nutrition of the British Paediatric Association. Is breast feeding beneficial in the UK? Arch. Dis. Child. 1994; 71: 376-80.

6 Position of the American Dietetic Association. Promotion of breast-feeding. J. Am. Diet. Assoc. 1997; 97: 662-6.

7 American Academy of Pediatricians, Policy Statement. Breastfeeding and the use of human milk. Pediatrics 1997; 100: 1035-9.

8 EURODIET Core Report. Submitted to the EU Commission.

9 WHO Regional Office for Europe. Health For All Data Base, European Region. Copenhagen: WHO, 1999. 